\title{
ANALISIS BEBAN KERJA FISIOLOGI PADA PROSES PEMBUATAN TAHU BERDASARKAN KONSUMSI ENERGI (STUDI KASUS: UD. LANCAR ABADI SAMARINDA)
}

\author{
Lina Dianati Fathimahhayati, Theresia Amelia, Andra Noor Syeha* \\ Program Studi Teknik Industri, Fakultas Teknik, Universitas Mulawarman \\ Email: linadianatif@gmail.com; triciapawitra@gmail.com; andranoorsyeha2@gmail.com
}

Artikel masuk : 24-09-2019

Artikel direvisi : 21-12-2019

Artikel diterima : 25-12-2019

*Penulis Korespondensi

\begin{abstract}
Abstrak - UD. Lancar Abadi merupakan usaha produksi tahu yang melayani kebutuhan sehari-hari masyarakat Samarinda. Kondisi lingkungan kerja UD. Lancar Abadi yang kurang baik, seperti suhu yang panas, kurangnya ventilasi, dan lantai licin dapat berpengaruh pada tingkat beban kerja pekerjanya. Beban kerja berlebih dapat mempengaruhi performansi kerja dan bisa berdampak pada penurunan produktivitas. Berdasarkan permasalahan tersebut, dilakukan penelitian yang bertujuan untuk mengukur tingkat beban kerja yang dialami pekerja pada UD. Lancar Abadi menggunakan konsumsi energi. Pengambilan data dilakukan pada 6 pekerja yang terdiri dari 5 laki-laki dan satu perempuan. Berdasarkan hasil kuesioner Nordic Body Map didapatkan rata-rata pekerja mengalami keluhan cukup sakit dan sakit. Keluhan diakibatkan karena proses pekerjaan masih minim alat bantu sehingga memerlukan tenaga otot. Konsumsi Energi pekerja untuk bagian penggilingan 2,59 kkal/menit, bagian perebusan sekaligus penyaringan $8,542 \mathrm{kkal} / \mathrm{menit}$, dan bagian penyaringan sekaligus pencetakan 7,06 kkal/menit. Pekerjaan penggilingan termasuk pekerjaan dengan beban kerja sedang, pekerjaan perebusan hingga pencetakan termasuk pekerjaan dengan beban kerja berat.
\end{abstract}

Kata kunci: Beban Kerja; Konsumsi Energi; Nordic Body Map

Abstract -- UD. Lancar Abadi is a tofu production business that serves the daily needs of the people of Samarinda. UD. Lancar Abadi has poor working condition, such as hot temperatures, lack of ventilation, and slippery floors that can affect the level of workload of workers. Excessive workload can affect work performance and can result in decreased productivity. Based on these problems, conducted research aimed at measuring the level of workload experienced by workers at UD. Lancar Abadi uses energy consumption. Data collection was carried out on 6 workers consisting of 5 men and one woman. Based on the results of the Nordic Body Map questionnaire, it was found that the average worker experienced quite sick and sick complaints. Complaints caused by the work process is still require muscle power. Worker Energy Consumption for the milling part is $2.59 \mathrm{kcal} /$ minute, the boiling part is at the same time filtering $8.542 \mathrm{kcal} /$ minute, and the filtering part is at once printing $7.06 \mathrm{kcal} / \mathrm{minute}$. Milling jobs have moderate workloads, boiling jobs until molding jobs have heavy workloads.

Keywords: Energy Consumption; Nordic Body Map; Workload

\section{PENDAHULUAN}

Manusia mempunyai peranan penting dalam menyelesaikan pekerjaan membuat suatu produk. Kemampuan pekerja yang bervariasi membuat hasil yang diperoleh berbeda-beda. Pemberian beban kerja yang berlebih dapat berdampak pada tingkat stress dan kesehatan pekerja (Purbasari \& Purnomo, 2019).
Pengukuran beban pekerjaan dapat dilakukan berdasarkan psikologi dan fisiologi (Diniaty, 2016; Fithri \& Anisa, 2017). Pendekatan fisiologi adalah teknik perancangan sistem kerja maupun tempat kerja yang memerlukan energi fisik otot manusia sebagai sumber tenaganya (Grandjean, 1980). Pendekatan fisiologi mempunyai tujuan mengurangi beban pekerjaan dalam 
rangka menurunkan tingkat kelelahan fisik pekerja (Åstrand, Rodahl, Dahl, \& Strømme, 2003).

Konsumsi energi merupakan parameter utama dalam penentuan tingkat beban kerja fisik (Iridiastadi \& Yassierli, 2014). Konsumsi energi pada waktu kerja dapat ditentukan dengan cara tidak langsung (pengukuran tekanan darah, aliran darah, komposisi kimia dalam darah, temperatur tubuh, tingkat penguapan dan jumlah udara yang dikeluarkan paru-paru) (Grandjean \& Kroemer, 1997), dan dapat diukur dengan cara pengukuran denyut nadi (Andriyanto \& Bariyah, 2012).

Denyut nadi merupakan pengukuran beban kerja berdasarkan gerakan otot (Purba \& Rambe, 2014). Denyut nadi dapat digunakan untuk mengukur kondisi fisik pekerja sebagai dasar tingkat kelelahan seorang pekerja. Semakin besar tingkat fluktuasi denyut nadi, mengindikasikan semakin besar tingkat beban kerja seseorang. Beban kerja yang berlebih ini dalam jangka panjang berdampak pada penurunan produktivitas seseorang yang diakibatkan kelelahan kerja (Helianty, Ario, \& Wahyuning, 2013).

UD. Lancar Abadi berdiri pada tahun 1997, merupakan usaha produksi tahu yang melayani kebutuhan sehari-hari masyarakat Samarinda. Kegiatan produksi tahu tersebut dilakukan pada kawasan Jln. Wiraswasta gg. Haji Mustam 1 Samarinda, Kalimantan Timur. UD. Lancar Abadi membuat 3 jenis tahu yaitu tahu putih, tahu sumedang, dan tahu kuning. Namun produksi tahu sumedang dan tahu kuning hanya dikerjakan satu kali dalam satu minggu dikarenakan lebih banyak permintaan untuk tahu putih tiap harinya. Produksi tahu dikerjakan secara manual dengan dibantu alat penggilingan. Pekerja harus bekerja dalam posisi selalu berdiri dan tubuh agak membungkuk. Selain itu suhu yang tinggi saat perebusan tahu, mempengaruhi fisik pekerja. Hal ini memunculkan kemungkinan terjadi kelelahan kerja yang tinggi bagi pekerja pada UD. Lancar Abadi. Kondisi lingkungan dengan lantai yang masih berupa tanah pada beberapa bagian akibat genangan air dan sisa pembakaran yang menggumpal, sehingga permukaan lantai menjadi kasar dan tidak rata. Selain itu, terdapat bau dari bahan baku, suhu yang panas, dan kurangnya ventilasi dapat mengganggu kenyamanan pekerja saat melakukan kegiatan produksi tahu.

Berdasarkan permasalahan tersebut, penelitian ini dilakukan bertujuan untuk menganalisis beban kerja pada pekerja UD. Lancar Abadi berdasarkan faktor fisiologi. Pengukuran kerja fisik dilakukan dengan mengukur konsumsi energi yang merupakan faktor utama dan tolak ukur sebagai penentu berat atau ringannya beban kerja tersebut. Hasil pengukuran ini diharapkan dapat menjadi dasar untuk perbaikan sistem kerja dalam rangka mengurangi beban kerja.

\section{METODE PENELITIAN}

Penelitian ini berfokus pada pengukuran kerja otot yang berhubungan dengan denyut nadi. Penelitian dilaksanakan pada bulan Juli s/d Oktober 2019 berlokasi di UD. Lancar Abadi. Pengumpulan data dilakukan dengan cara wawancara, kuesioner Nordic Body Map, dan pengukuran denyut nadi.

Wawancara dilakukan secara langsung kepada pihak pemilik usaha dan pekerja. Pengukuran Nordic Body Map dilakukan dengan melakukan wawancara langsung dengan 6 orang pekerja. Hal yang ditanyakan seperti usia, berat badan, tinggi badan, masa kerja, jenis pekerjaan, dan faktor kelelahan pada pekerja. Enam orang pekerja dengan 4 jenis pekerjaan yaitu 1 orang pekerja penggilingan, 2 orang pekerja memasak (perebusan) sekaligus penyaringan, 2 orang pekerja sebagai penyaringan dan pencetakan, dan 1 orang pekerja pengemasan.

Pengukuran denyut nadi dilakukan pada 3 jenis pekerjaan yaitu 1 orang pekerja penggilingan, 2 orang pekerja perebusan sekaligus penyaringan dan 2 orang pekerja penyaringan sekaligus pencetakan tahu pada titik waktu tertentu, yaitu 10 menit sebelum bekerja, 30 menit saat mulai bekerja, 30 menit sebelum selesai bekerja dan 30 menit setelah selesai bekerja. Masing-masing pengukuran dilakukan pengulangan sebanyak 3 kali. Evaluasi beban kerja dilakukan secara fisiologis berdasarkan denyut nadi dalam menentukan kebutuhan energi seorang pekerja (Ceesay et al., 1989).

\section{HASIL DAN PEMBAHASAN}

UD. Lancar Abadi merupakan usaha produksi tahu yang melayani kebutuhan seharihari masyarakat Samarinda dengan 3 jenis tahu yaitu tahu putih, tahu sumedang dan tahu kuning. Menjadi salah satu pemasok kebutuhan tahu masyarakat Samarinda, kegiatan produksi dikerjakan dari pukul 06.00 pagi - 11.00 siang dalam jumlah 6 orang pekerja dibagi dalam beberapa bagian pekerjaan (Tabel 1).

\section{Karakteristik Responden}

Penelitian ini menggunakan data 5 responden dengan rincian 4 pekerja laki-laki dan 1 pekerja perempuan dengan usia antara 18 tahun sampai 48 tahun. UD. Lancar Abadi memiliki waktu produksi selama 5 jam setiap harinya dari pukul 06.00 pagi sampai pukul 11.00 siang. Tidak ada waktu istirahat untuk seluruh bagian pekerjaan terkecuali bagian pengemasan yang hanya menunggu waktu mengemas saja 
ketika tahu sudah selesai diproduksi (Tabel 2).

Tabel 1. Pekerja dan Bagian Pekerjaan

\begin{tabular}{|c|c|c|}
\hline Nama & Bagian & Keterangan \\
\hline $\begin{array}{l}\text { Muhammad } \\
\text { Naim }\end{array}$ & Penggilingan & Pimpinan \\
\hline Arul & $\begin{array}{l}\text { Perebusan \& } \\
\text { Penyaringan }\end{array}$ & Anggota \\
\hline lqbal & $\begin{array}{l}\text { Perebusan \& } \\
\text { Penyaringan }\end{array}$ & Anggota \\
\hline Ribut & $\begin{array}{l}\text { Penyaringan } \\
\& \text { Pencetakan }\end{array}$ & Anggota \\
\hline $\begin{array}{c}\text { Aidil } \\
\text { Solekah }\end{array}$ & $\begin{array}{l}\text { Penyaringan } \\
\text { \& Pencetakan } \\
\text { Pengemasan }\end{array}$ & $\begin{array}{l}\text { Kepala } \\
\text { Produksi } \\
\text { Pemilik }\end{array}$ \\
\hline
\end{tabular}

Masa kerja pada pekerja UD. Lancar Abadi, masing-masing bagian pekerjaan memiliki masa kerja dari 1 tahun sampai 5 tahun bekerja. Durasi masa kerja masih dalam masa produktif.. $69,7 \%$ pekerja yang mempunyai masa kerja diatas 8 tahun mempunyai keluhan terhadap kelelahan kerja (Barus, 2017).

Tabel 2. Profil Responden

\begin{tabular}{ccc}
\hline Karakteristik & $\begin{array}{c}\text { Jumlah } \\
\text { Pekerja }\end{array}$ & Jawaban \\
\hline Jenis & 5 orang & Laki-laki \\
Kelamin & 1 orang & Wanita \\
Usia & 6 orang & 48 tahun \\
& & 35 tahun \\
& & 47 tahun \\
& & 22 tahun \\
& & 18 tahun \\
Lama Kerja & 5 orang & $06.00-11.00$ \\
& 1 orang & $07.00-11.00$ \\
Masa Kerja & 1 orang & 3 tahun \\
& 2 orang & 1 tahun \\
& 2 orang & 18 tahun \\
Pendidikan & orang & 5 tahun \\
Terakhir & 3 orang & SMP \\
\hline
\end{tabular}

Lingkungan kerja UD. Lancar Abadi memiliki suhu yang cukup tinggi (Gambar 1), selain itu kebisingan mesin penggilingan (Gambar 2), lantai licin (Gambar 3), lantai kasar (Gambar 4), ventilasi udara yang terhalang oleh bangunan rumah warga sehingga sirkulasi udara terhambat (Gambar 5) dan ketersediaan APD tidak mencukupi untuk seluruh pekerja (Gambar 6). Dari hasil wawancara kepada pemilik UD. Lancar Abadi, pekerja kurang menyukai menggunakan APD pada saat bekerja dan ada juga yang menggunakan APD.

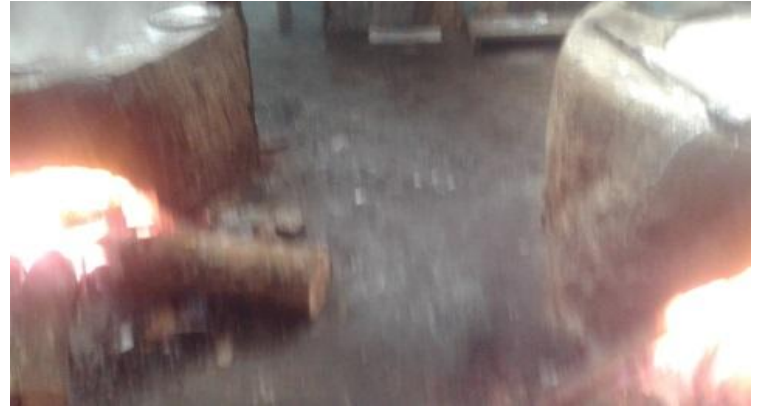

Gambar 1. Suhu Pembakaran

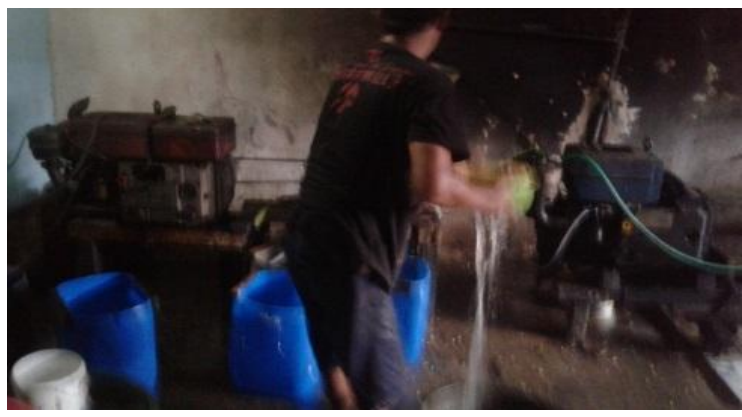

Gambar 2. Kebisingan mesin

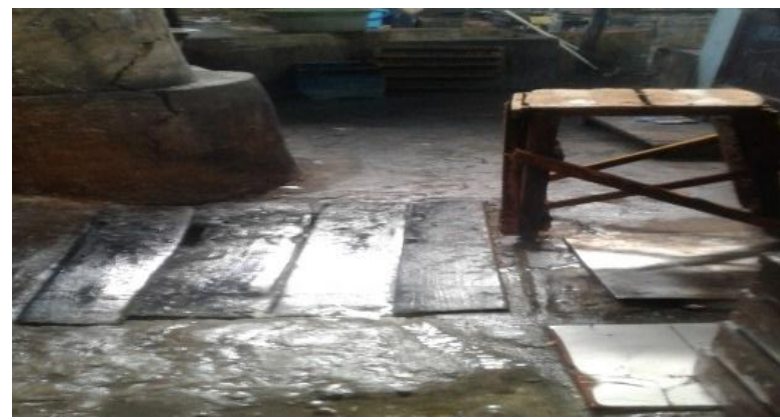

Gambar 3. Kondisi Lantai yang Licin

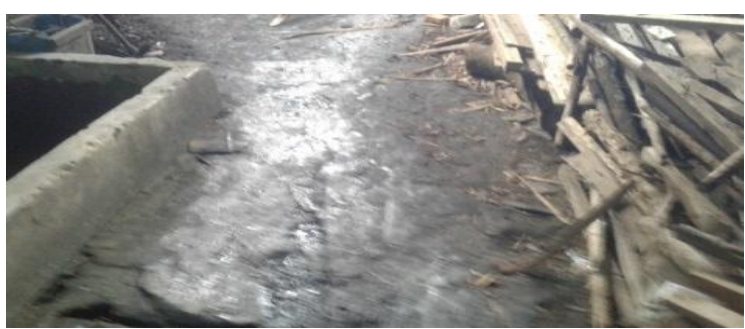

Gambar 4. Lantai yang Kasar

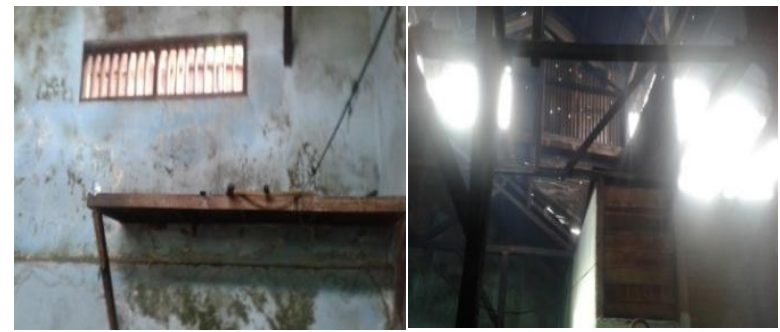

Gambar 5. Ventilasi Udara 


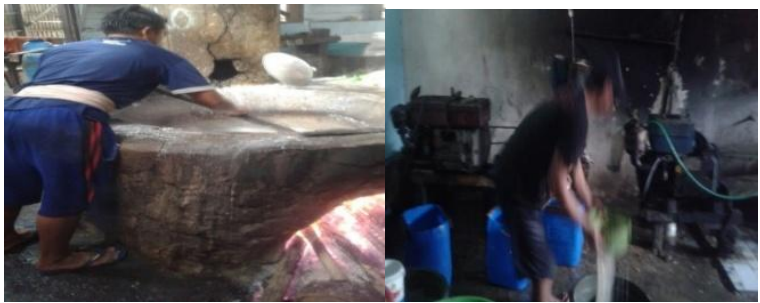

Gambar 5. Tidak Tersedianya APD

\section{Nordic Body Map}

Nordic Body Map merupakan metode pengukuran rasa sakit otot dengan cara menganalisis setiap bagian tubuh manusia. Metode ini bertujuan untuk mengetahui bagian otot yang mengalami keluhan dari tingkat tidak menyakitkan sampai tingkat menyakitkan (Setyanto, Efranto, Lukodono, \& Dirawidya, 2015). Penilaian menggunakan 5 skala likert dengan skala 1 sampai 5 .

Hasil pengukuran dengan Nordic Body Map menunjukkan rata-rata pekerja mengalami keluhan dari tingkat cukup sakit hingga sakit (Tabel 3). Pekerjaan penggilingan mengalami keluhan dalam skala 3 yaitu sakit. Proses penggilingan dilakukan dalam posisi yang selalu berdiri dan membungkuk karena posisi bak di permukaan lantai dengan ukuran bak dengan tinggi $25 \mathrm{~cm}$, diameter lingkaran $78 \mathrm{~cm}$, dan tinggi penggilingan $145 \mathrm{~cm}$ dari permukaan lantai. Oleh karena itu pekerja cepat merasakan lelah dan sakit pada bagian tubuhnya dan proses pekerjaan penggilingan dinyatakan tidak nyaman.

Pekerjaan perebusan dan penyaringan dilakukan oleh Arul (29 tahun) dan lqbal (18 tahun). Pekerja ini mengalami keluhan termasuk dalam skala 3 yaitu sakit dan skala 2 yaitu cukup sakit pada bagian tangan kiri dan kanan. Proses perebusan dan penyaringan dilakukan dalam posisi yang selalu berdiri dan agak membungkuk. Selain itu posisi pekerja terlalu dekat dengan tungku, sehingga dekat dengan suhu yang tinggi. Oleh karena itu pekerja lebih cepat merasakan lelah dan sakit pada bagian tubuhnya. Berdasarkan uraian tersebut diketahui proses pekerjaan perebusan dan penyaringan dinyatakan tidak nyaman dikerjakan.

Pekerjaan penyaringan dan percetakan dilakukan oleh Ribut (22 tahun) dan Aidil (35 tahun). Pekerja ini mengalami keluhan sakit dalam skala 3 yaitu sakit dan skala 2 yaitu cukup sakit pada bagian tangan kiri dan kanan. Proses penyaringan dan pencetakan dilakukan dalam posisi yang selalu berdiri dan membungkuk. Pekerja bisa cepat merasakan lelah dan sakit pada bagian tubuhnya dan disimpulkan bahwa proses pekerjaan penyaringan dan pencetakan dinyatakan tidak nyaman.

Pekerjaan pengemasan dilakukan oleh Solekah (48 tahun). Pekerja ini mengalami sakit dalam skala 2 yaitu cukup sakit. Adapun posisi kerja yang mempengaruhi pekerjaan. Pada proses pengemasan ini hanya dilakukan selama 30 menit saja dari 5 jam kerja. Oleh karena itu posisi kerja tidak begitu mempengaruhi kondisi fisiknya, sehingga dapat disimpulkan bahwa pekerjaan pada bagian pengemasan dinyatakan nyaman.

Beberapa usulan perbaikan untuk mengurangi kelelahan kerja antara lain:

a. pengaturan peletakan fasilitas dari penggilingan ke tempat perebusan, sehingga semakin memudahkan mengangkat benda pada ketinggian permukaan pinggang

b. Menggunakan ruang hampa atau gudang untuk meletakkan mesin bantu penggilingan agar kebisingan mesin berkurang.

c. Bagian pembakaran tungku ditutupi setelah membuat bahan bakar agar suhu panas beserta asap pembakaran langsung keluar melalui cerobong asap.

d. Membuat saluran pembuangan air di sekitar area bekerja agar air tidak tergenang dan menjalar kemana-mana. Kemudian selalu membersihkan lokasi lingkungan kerja yang terdapat sisa pembakaran kayu agar menghindari terjadinya luka akibat tersangkut di kaki.

e. Membuat ventilasi yang bisa membantu pergantian suhu ruangan yg tinggi, lihat kondisi arah angin apakah terhambat oleh dinding bangunan atau tidak.

\section{Konsumsi Energi}

Perhitungan tingkat beban kerja berdasarkan konsumsi energi dilakukan dengan cara perhitungan $\mathrm{VO}_{2}$ dan Heart Rate Range (HRR). Pengukuran denyut nadi dilakukan pada titik waktu tertentu, yaitu beberapa menit sebelum bekerja, 30 menit setelah mulai bekerja, 30 menit sebelum jam kerja selesai, dan 30 menit setelah selesai bekerja.

Berdasarkan pengolahan data awal diperoleh bahwa data sudah seragam dan cukup. Ketika data sudah mencukupi, maka pengukuran denyut nadi dapat dilakukan dengan menggunakan perhitungan yang digunakan pada pendekatan konsumsi energi pada persamaan (1), (2) dan (3). Pengukuran konsumsi oksigen $\left(\mathrm{VO}_{2}\right)$ dengan memperhatikan hubungan energy expenditure dengan kecepatan heart rate (denyut jantung) (Iridiastadi \& Yassierli, 2014)

$\mathrm{VO}_{2}=-1,168+0,020 \mathrm{HR}-0,035 \mathrm{~A}+0,019 \mathrm{~W}$

(liter/menit) 
Tabel 3. Rasa Sakit Bagian Tubuh Pekerja

\begin{tabular}{llcc}
\hline \multicolumn{1}{c}{ Lokasi Keluhan } & Jumlah & $\begin{array}{c}\text { Tingkat } \\
\text { Keluhan }\end{array}$ & Keterangan \\
\hline Bahu kiri (2) & 6 orang & 3 & Sakit \\
Bahu kanan (3) & 6 orang & 3 & Sakit \\
Lengan atas kiri (4) & 6 orang & 3 & Sakit \\
Punggung (5) & 6 orang & 3 & Sakit \\
Lengan atas kanan (6) & 6 orang & 3 & Sakit \\
Pinggang (7) & 5 orang & 3 & Sakit \\
Tangan kiri (16) & 4orang & 2 & Cukup Sakit \\
& 2orang & 3 & Sakit \\
Tangan kanan (17) & 4 orang & 2 & Cukup Sakit \\
& 2 orang & 3 & Sakit \\
Lutut kiri (20) & 1 orang & 3 & Sakit \\
Lutut kanan (21) & 1 orang & 3 & Sakit \\
Betis kiri (22) & 1 orang & 2 & Cukup Sakit \\
Betis kanan (23) & 5 orang & 3 & Sakit \\
Pergelangan kaki kiri (24) & 1 orang & 2 & Cukup Sakit \\
Pergelangan kaki kanan & 1 orang & 3 & Sakit \\
(25) & & 3 & Sakit \\
Telapak kaki kiri (26) & 1 orang & 2 & Sakit \\
Telapak kaki kanan (27) & 5 orang & 3 & Cukup Sakit \\
& 5 orang & 2 & Sakit \\
& & 3 & Cukup Sakit \\
& & & Sakit \\
\hline
\end{tabular}

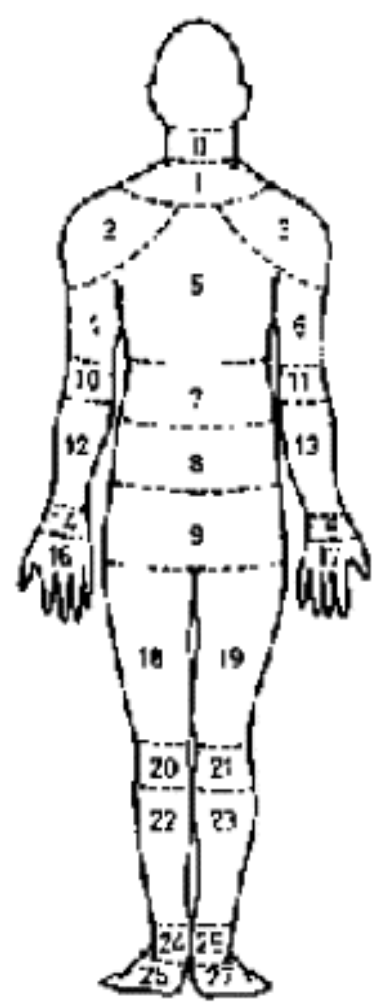

Pendekatan lain menyarankan penggunaan data denyut jantung yang dibandingkan dengan maksimal heart rate yang mungkin dimiliki oleh seorang individu. Denyut jantung maksimal dipercaya merupakan fungsi dari usia dan dapat dinyatakan sebagai berikut:

$$
\begin{aligned}
\text { Max HR } & =220-\text { umur } \\
& =260-(0,62 \times \text { umur) }, \text { atau } \\
& =190-0,62 \times \text { (umur }-25)
\end{aligned}
$$

Peningkatan yang potensial dalam denyut nadi dari istirahat sampai kerja maksimum $\mathrm{HR}_{\text {kerja }}$ diukur pada saat melakukan pekerjaan. HRrest diukur setelah 5 menit sebagai pekerja dengan istirahat (Hayati, Marzban, \& Asoodar, 2015; PerkiöMäkelä \& Hentilä, 2005). HRmaks ilai setelah setiap tugas kerja di Borg RPE Skala 20, mulai dari 6 hingga 20, dimana 6 berarti tidak ada tenaga sama sekali" dan 20 berarti tenaga maksimal (Borg, 1970)

$\operatorname{HRR}(\%)=\frac{100\left(\mathrm{HRR}_{\text {keja }}-H R R_{\text {rest }}\right)}{H R R_{\text {maks }}-H R R_{\text {rest }}}$

$\begin{array}{ll}\text { HRR } & \text { Heart Rate Range } \\ \text { HRkerja } & : \text { denyut jantung diukur saat } \\ \text { HRrest } & : \text { dekerja } \\ \text { denyut jantung diukur saat }\end{array}$

HRmaks : denyut jantung maksimal

Pengukuran energi yang dibutuhkan pekerja umumnya melalui pengukuran jumlah oksigen yang dikonsumsi per satuan waktu (liter/menit), hal ini dimungkinkan dengan asumsi rata-rata $5 \mathrm{kkal}$ energi dapat dihasilkan dari setiap liter oksigen yang digunakan. Hasil yang didapatkan di UD.Lancar Abadi, konsumsi oksigen pekerja berturut-turut saat bekerja untuk bagian penggilingan $0,815 \mathrm{liter} / \mathrm{menit}=2,59 \mathrm{kkal} /$ menit, bagian perebusan sekaligus penyaringan 1,708 liter $/$ menit $=8,542 \mathrm{kkal} / \mathrm{menit}$, dan bagian penyaringan sekaligus pencetakan 1,412 liter $/$ menit $=7,06 \mathrm{kkal} /$ menit. Berdasarkan tabel Kroemer (Iridiastadi \& Yassierli, 2014) hasil tersebut menunjukkan pekerjaan pada bagian penggilingan termasuk pekerjaan yang agak berat atau sedang, kemudian pekerjaan pada bagian perebusan hingga pencetakan termasuk pekerjaan yang berat. Berdasarkan perhitungan $\mathrm{VO}_{2}$, dapat disimpulkan bahwa pekerjaan aman bagi pekerja karena $\mathrm{VO}_{2} \mathrm{Max}$ masih berada di bawah rentang 3,5 $\pm 0,55$ (tabel 4).

Untuk itu dilakukan pendekatan lain yang menggunakan data denyut jantung yang dibandingkan dengan maksimal heart rate (Max HR) yang dimiliki setiap pekerja. Setelah max HR diketahui, kemudian dihubungkan dengan Heart 
Tabel 4. Konsumsi Oksigen per Pekerja

\begin{tabular}{llcc}
\hline \multicolumn{1}{c}{ Nama } & \multicolumn{1}{c}{ Bagian } & $\begin{array}{c}\mathbf{V O}_{2} \\
\text { Liter/menit }\end{array}$ & $\begin{array}{c}\text { Konsumsi Energi } \\
\text { Kkal/menit }\end{array}$ \\
\hline Muhammad Naim & Penggilingan & 0,815 & 2,59 \\
Arul & Perebusan dan penyaringan & 1,111 & 5,555 \\
lqbal & Perebusan dan penyaringan & 2,306 & 11,53 \\
Ribut & Penyaringan dan pencetakan & 1,966 & 9,83 \\
Aidil & Penyaringan dan pencetakan & 0,858 & 4,29 \\
\hline
\end{tabular}

Tabel 5. Heart Rate Range (HRR\%)

\begin{tabular}{llccc}
\hline \multicolumn{1}{c}{ Nama } & \multicolumn{1}{c}{ Bagian } & $\begin{array}{c}\text { HR } \\
\text { Max }\end{array}$ & $\begin{array}{c}\text { HRR } \\
\%\end{array}$ & Keterangan \\
\hline Muhammad Naim & Penggilingan & 173 & 14,41 & Agak Berat \\
Arul & Perebusan dan penyaringan & 191 & 17,05 & Berat \\
lqbal & Perebusan dan penyaringan & 202 & 16,05 & Berat \\
Ribut & Penyaringan dan pencetakan & 198 & 11,88 & Berat \\
Aidil & Penyaringan dan pencetakan & 185 & 16,64 & Berat \\
\hline
\end{tabular}

Rate Range (HRR) untuk mengetahui peningkatan persentase denyut nadi setiap pekerja. Untuk pekerjaan selama 8 jam, nilai HRR yang disarankan tidak melebihi 33\% (Iridiastadi \& Yassierli, 2014). Hasil yang didapat di UD. Lancar Abadi, menunjukkan $\mathrm{HRR} \%$ pada bagian pekerjaan penggilingan dengan nama Muhammad Naim $14,41 \%$, bagian perebusan sekaligus penyaringan dengan nama Arul $17,05 \%$ dan lqbal $16,05 \%$, bagian penyaringan sekaligus pencetakan dengan nama Ribut $11,88 \%$ dan Aidil $16,64 \%$. Pada UD. Lancar Abadi memiliki pekerjaan selama 5 jam kerja tanpa adanya waktu istirahat, jadi nilai HRR yang disarankan tidak melebihi 20 $\%$. Dapat disimpulkan bahwa pekerjaan yang dilakukan selama 5 jam tidak akan menimbulkan kelelahan pada pekerjanya, karena HRR $\%<20 \%$ (Tabel 5).

Beberapa usulan perbaikan untuk mengurangi kelelahan kerja antara lain:

1. Melakukan pengujian dan evaluasi kinerja secara berkala untuk mendeteksi adanya kelelahan dini dan segera menentukan langkah pengendaliannya.

2. Pekerja harus selalu memperhatikan pola makan dan gizi yang benar agar mampu bekerja secara maksimal.

3. Mengatur waktu istirahat tidur malam untuk memulihkan kembali bagian-bagian tubuh yang terasa sakit.

4. Olahraga secara teratur bahkan berkonsultasi dengan dokter untuk tetap menjaga kondisi tubuh.
5. Relaksasi ketika terlalu lama berdiri yang dapat memicu kelelahan bekerja.

6. Sempatkan sedikit waktu untuk bercanda atau tertawa dengan teman untuk menghindari stress akibat bekerja yang membuat bosan.

\section{KESIMPULAN}

Hasil Nordic Body Map menunjukkan ratarata pekerja mengalami keluhan dari tingkat cukup sakit hingga sakit. Keluhan ini banyak disebabkan oleh lingkungan kerja yang kurang nyaman dan minimnya alat bantu untuk memperingan pekerjaan. Berdasarkan hasil pengukuran data denyut nadi yang dilakukan di UD. Lancar Abadi per bagian pekerjaan masih dinyatakan aman dengan $\mathrm{VO}_{2}$ (liter/menit) pada 3 bagian pekerjaan, semuanya masih di dalam batas rentang 3,5 \pm 0,55 liter/menit, HRR\% (Heart Rate Range), semuanya berada dibawah $20 \%$, ratarata denyut nadi pada saat bekerja $<$ Max HR. Konsumsi Energi pekerja untuk bagian penggilingan $2,59 \mathrm{kkal} /$ menit, bagian perebusan sekaligus penyaringan $8,542 \mathrm{kkal} /$ menit, dan bagian penyaringan sekaligus pencetakan 7,06 kkal/menit. Pekerjaan penggilingan termasuk pekerjaan dengan beban kerja sedang, pekerjaan perebusan hingga pencetakan termasuk pekerjaan dengan beban kerja berat. Penelitian selanjutnya dapat dilakukan dengan perancangan alat bantu kerja untuk mengurangi tingkat kelelahan kerja dan beban kerja pada proses perebusan, penyaringan dan percetakan. 


\section{DAFTAR PUSTAKA}

Andriyanto, A., \& Bariyah, C. (2012). Analisis beban kerja operator mesin pemotong batu besar (sirkel $160 \mathrm{~cm}$ ) dengan menggunakan metode 10 denyut. Jurnal IImiah Teknik Industri, 11(2), 136-143.

Åstrand, P.-O., Rodahl, K., Dahl, H. A., \& Strømme, S. B. (2003). Textbook of work physiology: physiological bases of exercise. Human Kinetics.

Barus, Y. R. (2017). Perbedaan Kelelahan Kerja Ditinjau dari Shift Kerja pada Karyawan PT. Tirta Alpin Makmur. Universitas Medan Area.

Borg, G. (1970). Perceived exertion as an indicator of somatic stress. Scandinavian Journal of Rehabilitation Medicine, 2(2), 92 98.

Ceesay, S. M., Prentice, A. M., Day, K. C., Murgatroyd, P. R., Goldberg, G. R., Scott, W., \& Spurr, G. B. (1989). The use of heart rate monitoring in the estimation of energy expenditure: a validation study using indirect whole-body calorimetry. British Journal of Nutrition, 61(2), 175-186.

Diniaty, D. D. (2016). Analisis Beban Kerja Fisik dan Mental Karyawan di Lantai Produksi pada PT Pesona Laut Kuning. Jurnal Sains Dan Teknologi Industri, 13(2), 203-210.

Fithri, P., \& Anisa, W. F. (2017). Pengukuran Beban Kerja Psikologis dan Fisiologis Pekerja di Industri Tekstil. Jurnal Optimasi Sistem Industri, 16(2), 120-130.

Grandjean, E. (1980). Fitting the task to the man: an ergonomic approach. Taylor \& Francis.

Grandjean, E., \& Kroemer, K. H. E. (1997). Fitting the task to the human: a textbook of occupational ergonomics. Philadelphia: CRC press.

Hayati, A., Marzban, A., \& Asoodar, M. A. (2015). Ergonomic assessment of hand cow milking operations in Khuzestan Province of Iran. Agricultural Engineering International: CIGR Journal, 17(2), 140-145.

Helianty, Y., Ario, M. G. D., \& Wahyuning, C. S. (2013). Perbaikan Lingkungan Kerja Pada Bagian Permesinan Dengan Kriteria Beban Fisiologis Kerja. REKA INTEGRA, 1(2), 280289.

Iridiastadi, H., \& Yassierli. (2014). Ergonomi suatu pengantar. Bandung: PT. Remaja Rosdakarya.

Perkiö-Mäkelä, M., \& Hentilä, H. (2005). Physical work strain of dairy farming in loose housing barns. International Journal of Industrial Ergonomics, 35(1), 57-65.

Purba, E., \& Rambe, A. J. M. (2014). Analisis Beban Kerja Fisiologis Operator Di Stasiun Penggorengan Pada Industri Kerupuk.
Jurnal Teknik Industri USU, 5(2), 11-16.

Purbasari, A., \& Purnomo, A. J. (2019). Penilaian Beban Fisik Pada Proses Assembly Manual Menggunakan Metode Fisiologis. SIGMA TEKNIKA, 2(1), 123-130.

Setyanto, N. W., Efranto, R., Lukodono, R. P., \& Dirawidya, A. (2015). Ergonomics analysis in the scarfing process by OWAS, NIOSH and Nordic Body Map's method at slab steel plant's division. Ergonomics, 4(3), 10861093.

Sitohang, D. R., Winaningthias, M., \& Iridiastadi, H. (2010). Evaluasi Beban Fisiologis Pada Industri Manufaktur (Industri Pembuatan Komponen Pesawat Terbang dan Industri Sepatu).J@ Ti Undip: Jurnal Teknik Industri, 5(2), 119-126. 